\title{
New Twin Education Website www.twinsandmultiples.org
}

\author{
David Hay and Pat Preedy
}

There is something very special about being a twin or higher multiple. There are also special challenges that may face parents and teachers in such a situation. The aim of this website is to help everyone more clearly understand the implications of a multiple birth throughout the school years, since there are some concerns such as the separation of multiples in class which simply do not arise with singleborn children. While most multiples are twins, there are an increasing number of triplets and higher multiples. So how do we best provide support for such families and those who teach the children? Multiples are more likely than other children to be seen by a whole range of other professionals, including speech therapists and educational psychologists who will find relevant material on the site

The website was launched at the ISTS (International Society for Twin Studies) Congress on Friday 6th July in London, England by Professor Sir Michael Rutter. Parents and Professionals expressed great interest in the site particularly as it provides downloadable materials and an opportunity for parents, professionals and adolescent multiples to discuss issues via forums. The site also provides "multiple links" enabling users to easily access information from a range of other sites including parent organisations. The site is designed to be relevant to parents and professionals from around the world giving, for the first time, a global resource that provides easy access to both information and resources.

The website is hosted by Curtin University, Australia, and has been funded by AMBA (Australian Multiple Births Association), Tamba (Twins and multiple births association) -via The Cherry Rowland Trust and Curtin
University, Australia. Members of the Council Of Multiple Birth Organisations (COMBO) endorsed the website and agreed to promote it within their own countries.

\section{About the Authors}

David Hay has worked with multiple birth families for 25 years. In the late 1980's along with the Australian Multiple Birth Association, he developed the 'Twins in School' program, a national survey of parents and teachers, followed by many workshops and a very successful booklet 'Twins in School'. Pat Preedy's interest in multiples arose through her role as a Head Teacher faced with 9 sets of multiples starting school in the same year. She has completed a $\mathrm{PhD}$ thesis which complements and extends many of the issues first raised in the Australian work. Although countries differ so much in their education systems, the fact that the same issues and dilemmas arise led the authors to decide a website was the best way of sharing their many years experience of multiples in school.

\section{The Website Structure}

This website is divided into the following sections:

- Multiple Facts and Figures

- Pre-School

- The School Years

- Special Needs

- Multiple Links

Each of the information sections has downloadable resources and a scenario that emphasises the points in that section. There are no answers to the scenarios, the idea being that the Forums and Bulletin Board in the final Multiple Links section could be the venue for discussing how to handle these scenarios.

\section{Multiple Facts and Figures}

One child in 36 is now a twin or higher multiple and this section introduces some of the basic information that teachers need to know to best help multiples and their families. Telling if multiples are identical or not is an obvious one, but the fact that nonidentical twins are more often born to older mothers or as a result of assisted reproduction may potentially change the family dynamics in ways of which teachers need to be aware. Unfortunately multiple pregnancies are higher risk and some of the issues around premature delivery and other complications are introduced.

\section{Pre-school}

Multiples are more likely to experience delays in speech and language development, and we examine why this may happen, how to begin to identify it and what to do about it, linking to a Curtin University website that details the only language program specifically developed for multiples. Intervention needs parental input and so some of the pressures on parents of multiples have to be recognised. At this age multiples are developing their relationships and the topics of comparison, competition and closeness are introduced. The section concludes with the topic of school readiness and there is a questionnaire to help parents and teachers discuss common concerns.

\section{The School Years}

Whether multiples should or should not be in the same class is a constant topic of debate and this section commences with a discussion as to what is best for particular families, recognising there is no single solution. A downloadable 
separation checklist and questionnaire for parents and teachers is provided to provide a framework for discussion.

Nationwide studies in Australia and more recently in the UK agree on the key questions to consider. How multiples perform at school relative to singleborn children is examined through large surveys in the UK and Australia. With the move to national assessment tests in many countries, there are particular concerns for multiple birth families, especially when the children differ in performance. Secondary school poses two pressures on multiples as they choose subjects and careers (what if they want to do the same as their twin?) and as they seek independence from each other as well as from their parents. Finally there is some advice about multiples at school, both in the classroom and in their recognition in school policy.

\section{Supporting Multiples with Special Needs}

Sadly there are some difficulties at school that are more common in multiples and four of the most common ones are examined. The higher rate of reading problems is associated with the speech and language difficulties discussed in the Preschool section and with the higher rates of Attention Deficit Hyperactivity Disorder (ADHD). For many ADHD remains a controversial diagnosis, but recognising it and managing it in the home and classroom can go a long way to helping these children reach their full potential. There are higher risks for pregnancy and delivery, which may lead to several significant problems such as cerebral palsy and intellectual disability. It is not just educating the multiple with special needs that matters, but also considering how the other multiple(s) and indeed the whole family are affected. The same risks that lead to more multiples having special needs also leads to a higher mortality before and at birth. Schools may need to be aware of this because of the extra pressures that can face the surviving multiples in the family.

\section{Multiple Links}

The final section links this website to the growing multiple birth community. Spearheaded by the International Society for Twin Studies this includes researchers throughout the world inter- ested in multiple births and the international network of support organisations for families. Curtin University is supporting the establishment of community links through forums for interactive communication and bulletin boards where people can raise issues and seek advice from those in similar situations. There are three sets of such links, one for multiples themselves, one for parents and one for professionals encountering particular situations where shared experiences may help.

\section{Conclusion}

The worldwide web provides new and expanding opportunities for communication. Unlike the written word, the website can quickly and easily be updated. Users can easily go to the sections that they are interested in and obtain materials for immediate use.

Thanks are due to Design One, the company responsible for designing and producing the website. Their knowledge and expertise has ensured that the site is of high quality with many attractive features including a carousel of multiple photographs on the home page. 